East African Medical Journal Vol. 77 No. 9 September 2000

DOCTORS LIFESTYLE IN ENUGU, NIGERIA

M. N. Aghaji, MBBS, FWACP, Department of Community Medicine, University of Nigeria Teaching Hospital Enugu, Nigeria.

Request for reprints to: Dr. M. N. Aghaji, 26 Park Avenue, G.R.A., Enugu, Nigeria.

\title{
DOCTORS LIFESTYLE IN ENUGU, NIGERIA
}

\author{
M. N. AGHAJI
}

\begin{abstract}
Objectives: To assess the prevalence of tobacco use, alcohol misuse, physical inactivity, obesity and to study associated factors.

Design: A cross-sectional survey using self-administered questionnaire.

Setting: Health facilities in Enugu, Nigeria.

Subjects: Three hundred and sixty two registered medical doctors — ninety two females and two hundred and seventy males

Main outcome measures: Self-reported data on tobacco use, cigarette smoking, weekly unit of alcoholic drink consumption, weekly participation in leisure physical activity, the most recent weight and height measurents.

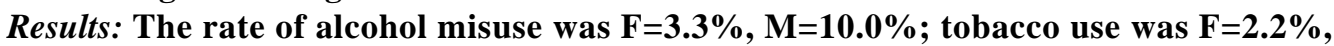
$\mathbf{M}=\mathbf{2 4 . 4 \%}$ while only males currently smoked cigarettes $(\mathbf{2 1 . 9 \%})$. The prevalence of over weight was $\mathrm{F}=\mathbf{5 7 . 6 \%}, \mathrm{M}=\mathbf{6 8 . 1} \%$, while physical inactivity was $\mathrm{F}=\mathbf{6 8 . 5} \%, \mathrm{M}=\mathbf{5 9 . 6 \%}$. The lifestyle of the doctors was significantly associated with demographic factors and was also inter-related. The female doctors were more homogenous in behaviour than the males. Conclusion: Promotion of good dietary habits, physical activity and smoking cessation among these doctors is advocated
\end{abstract}

\section{INTRODUCTION}

Individual behaviours can induce adverse changes in the biochemical and physiological properties of the body and these can lead to the development of poor physical functioning, many injuries, chronic diseases and overall mortality. And even after the development of symptomatic disease, they continue to contribute to their progression and prognosis. Notorious among these risky behaviours are tobacco use, alcohol misuse, physical inactivity and poor dietary habits which are linked to obesity(1-4).

Tobacco use has been implicated as a cause of ischaemic heart disease, cerebrovascular diseases, chronic obstructive pulmonary disease, cancers of the lung, mouth oesophagus, larynx and pharynx. Tobacco smoking was estimated to have caused thirteen per cent of all cancer deaths in developing countries in 1990 and by 1995, the total deaths attributable to tobacco use in sub-Saharan Africa alone was 95,000(5). Several researchers have shown that alcohol misuse can lead to poisoning, accidents, violence and an increase in the incidence of liver cirrhosis and certain malignancies $(2,3,6,7)$. They also noted that, excessive alcohol consumption is associated with an increase in the incidence of cardiomyopathy, cardiac arrhythmias, hypertension, stroke and sudden death. Poor dietary habits on the other hand, are linked with obesity which has adverse effect on both health and longevity. Many studies have found a positive relationship between obesity and the occurrence of diabetes mellitus, hypercholesterolaemia, coronary heart disease, angina pectoris, hypertension, stroke and all-cause mortality(24). Reviews of epidemiological studies have revealed the numerous health benefits of habitual physical activity which include, the maintenance of body weight and muscle tissue. Long-term physical activity also reduces the risk of hypercholesterolaemia, diabetes mellitus, cancer of the breast and colon, hypertension, coronary heart disease and other cardiovascular diseases(2-4).

The effective control of all these conditions requires lifestyle modification of the population at risk, and so prevalence studies of lifestyle is very important. Additionally, doctors' lifestyle is critical in the promotion of healthy behaviours among the populace. This study assessed the prevalence of tobacco use, alcohol misuse, physical inactivity and obesity among doctors in Enugu, Nigeria. It also looked into the factors associated with these behaviours. 


\section{MATERIALS AND METHODS}

Enugu city was the capital of the former Eastern Nigeria, with an estimated population of 464,514 in 1991. As of 1998 there were about 400 registered doctors working in the city. The registered health facilities within the town include three tertiary and two secondary health institutions, 14 primary health care centres and about 147 private hospitals/clinics.

All registered medical doctors practising in Enugu city were targeted for this cross-sectional study which was carried out from May to August 1999. Their names and addresses were obtained from the register of the Nigeria Medical and Dental Council, Enugu. Relevant data were collected using selfadministered questionnaires distributed at their workplaces by the investigator and four trained health workers. Information was obtained about their tobacco and alcohol use, participation in leisure physical activity, most recent weight and height measurements using one month recall. Enquires were also made about the following socio-demographic data: age, sex, marital status, specialty and years of medical practice.

Data were analysed by computer using the Epi-Info version 5 software. $T$ and $\chi 2$-tests were used to assess for the significance of findings at $95 \%$ confidence limits. Data were analysed separately for males and females.

Tobacco use and cigarette smoking were measured according to the World Health Organisation guidelines(8): Current cigarette smoker $=$ daily + occassional smokers. Alcohol consumption was classified using the British Department of Health guidelines(9): Alcohol Misuse $=$ alcohol consumption levels of $\geq 15$ units for women and $\geq 22$ units for men. 1 glass of wine $=1$ unit

1 bottle of wine $=7$ units

1 public bar shot of spirits $=1$ unit

1 bottle of spirits $=28$ units

1 bottle of Nigerian beer/ stout / palmwine $(60 \mathrm{cl})=2$ units Nigeria beer has an alcohol content of $4.0-4.5 \mathrm{gm} \%$, while that of palmwine (an indigenous alcoholic beverage tapped from the palm tree) varies between $0.3-3.8 \mathrm{gm} \%(10)$ according to the tree type and shelf life of the drink.

The European societies of Cardiology/Atheroscleroses/ Hypertension guideline(2) was used in grading the degree of obesity and physical activity of the respondents. Degree of obesity was estimated from calculations of body mass index $\left(\mathrm{BMI}=\right.$ weight $/$ height $\left.^{2}\right)$.

\section{Overweight $=B M I \geq 25 \mathrm{~kg} \mathrm{~m}^{-2}$}

Adequate physical activity involves aerobic use of large muscle groups at about $60 \%$ functional capacity for at least twice weekly for 90 minutes per week.

\section{RESULTS}

Study population: Of the 400 questionnaires distributed, 382 were returned giving a response rate of $95.5 \%$. However, twenty were incompletely filled which left 362 for analysis. The respondents were made up of 92 $(25.4 \%)$ females and $270(74.7 \%)$ males while their mean age was $37.4 \pm 10.1$ years. The majority were married 200 $(57.0 \%), 151(43.0 \%)$ single and $11(3.0 \%)$ divorced or widowed. Their specialties of training were as follows; general practice $112(30.9 \%)$, surgery $79(21.8 \%)$, medicine $56(15.5 \%)$, obstetric and gynaecology $30(8.3 \%)$, paediatrics $28(7.7 \%)$, laboratory medicine $19(5.2 \%)$ and house officers $38(10.5 \%)$.

Alcohol misuse: Males reported a slighty higher prevalence for alcohol misuse than females $(\mathrm{M}=10.0 \%$, $\mathrm{F}=3.3 \%$ ); Table 1 . The mean weekly units of alcoholic drink consumption is significantly higher in males (15.2 units) than females (7.6 units). None of the female doctors reported heavy drinking ( $\geq 35$ units) unlike 3.7\%( $\mathrm{N}=270)$ of the male doctors who drank $\geq 50$ units per week. In both sexes, the rate of alcohol misuse was not affected by age, marital status and specialty Table 2 .

Table 1

Prevalence of behavioural risk factors by sex.

\begin{tabular}{|c|c|c|c|c|}
\hline Risk factor & $\begin{array}{l}\text { Female } \\
\mathrm{N}=92 \\
\text { No }(\%)\end{array}$ & $\begin{array}{l}\text { Male } \\
\mathrm{N}=270 \\
\text { No }(\%)\end{array}$ & $\begin{array}{l}\text { Total } \\
\mathrm{N}=362 \\
\text { No }(\%)\end{array}$ & $\mathrm{P}$ value \\
\hline Alcohol misuse & $3(3.3)$ & $27(10.0)$ & $30(8.3)$ & 0.70 \\
\hline Mean weekly alcohol unit & $7.6 \pm 8.2$ & $15.2 \pm 22.1$ & $14.4 \pm 21.2$ & 0.049 \\
\hline Tobacco use & $2(2.2)$ & $66(24.4)$ & $68(18.8)$ & $0.000005^{*}$ \\
\hline Cigarette smoking & - & $59(21.9)$ & $59(16.3)$ & $0.000002^{*}$ \\
\hline Overweight & $53(57.6)$ & $157(58.1)$ & $210(58.0)$ & 0.975 \\
\hline Mean BMI $\left(\mathrm{Kg} \mathrm{m}^{-2}\right)$ & $25.2 \pm 3.6$ & $25.6 \pm 3.9$ & $25.5 \pm 3.8$ & 0.649 \\
\hline Physical inactivity & $63(68.5)$ & $161(59.6)$ & $224(61.9)$ & 0.166 \\
\hline Mean number of risks & $1.3 \pm 0.7$ & $1.5 \pm 0.8$ & $1.5 \pm 0.8$ & $0.038 *$ \\
\hline
\end{tabular}


Table 2

\begin{tabular}{|c|c|c|c|c|c|c|c|c|c|}
\hline & \multicolumn{2}{|c|}{$\begin{array}{l}\text { Sample size } \\
\text { (No) }\end{array}$} & \multicolumn{2}{|c|}{$\begin{array}{l}\text { Alcohol misuse } \\
\qquad(\%)\end{array}$} & \multirow{2}{*}{$\begin{array}{c}\begin{array}{c}\text { Smoking } \\
(\%)\end{array} \\
\mathrm{M}\end{array}$} & \multicolumn{2}{|c|}{$\begin{array}{c}\text { Overweight } \\
(\%)\end{array}$} & \multicolumn{2}{|c|}{$\begin{array}{c}\text { Physical inactivity } \\
(\%)\end{array}$} \\
\hline & $\mathrm{F}$ & M & $\mathrm{F}$ & M & & $\mathrm{F}$ & M & $\mathrm{F}$ & M \\
\hline \multicolumn{10}{|l|}{ Age (years): } \\
\hline $20-29$ & 26 & 47 & - & 12.8 & 31.9 & 46.2 & 40.4 & 65.4 & 70.2 \\
\hline $30-39$ & 45 & 132 & 6.7 & 11.4 & 23.5 & 53.3 & 57.6 & 71.1 & 53.8 \\
\hline $40-49$ & 17 & 51 & - & 9.8 & 13.7 & 76.5 & 68.6 & 70.6 & 52.9 \\
\hline $50+$ & 4 & 40 & - & 2.5 & 15.0 & 100.0 & 67.5 & 50.0 & 75.0 \\
\hline p-value & & & 0.981 & 0.366 & $0.023^{*}$ & $0.012 *$ & $0.020 *$ & 0.930 & $0.030 *$ \\
\hline \multicolumn{10}{|l|}{ Marital status: } \\
\hline Married & 57 & 143 & 3.5 & 7.7 & 18.2 & 61.4 & 63.6 & 66.7 & 62.9 \\
\hline Single & 29 & 122 & 3.4 & 13.1 & 26.2 & 51.7 & 50.8 & 69.0 & 55.7 \\
\hline $\mathrm{p}$-value & & & 1.000 & 0.211 & 0.153 & 0.529 & $0.048^{*}$ & 0.977 & 0.287 \\
\hline \multicolumn{10}{|l|}{ Specialty: } \\
\hline House officer & 10 & 28 & - & 14.3 & 35.7 & 50.0 & 35.7 & 80.0 & 78.6 \\
\hline Medicine & 17 & 39 & - & 10.3 & 12.8 & 70.6 & 64.1 & 64.7 & 66.7 \\
\hline Lab. medicine & 4 & 15 & - & 6.7 & 13.3 & 25.0 & 73.3 & 75.0 & 66.7 \\
\hline Obs. and gynae. & 2 & 28 & - & 14.3 & 21.4 & 50.0 & 64.3 & 100.0 & 64.3 \\
\hline Surgery & 13 & 66 & 7.7 & 6.1 & 16.7 & 61.5 & 59.1 & 53.8 & 62.1 \\
\hline Paediatrics & 15 & 13 & - & 7.7 & 23.1 & 73.3 & 38.5 & 66.7 & 61.5 \\
\hline General practice & 31 & 81 & 6.5 & 11.1 & 27.2 & 48.4 & 61.7 & 71.0 & 44.4 \\
\hline p-value & & & 0.754 & 0.851 & 0.235 & 0.437 & 0.097 & 0.793 & $0.036^{*}$ \\
\hline
\end{tabular}

*Indicate $\chi 2$ tests with $\mathrm{p}$-values $<0.05$

Table 3

Relationship between lifestyles

\begin{tabular}{|c|c|c|c|c|c|c|c|c|c|c|}
\hline & \multicolumn{2}{|c|}{$\begin{array}{c}\text { Sample size } \\
\text { No }\end{array}$} & \multicolumn{2}{|c|}{$\begin{array}{c}\text { Alcohol misuse } \\
\%\end{array}$} & \multicolumn{2}{|c|}{$\begin{array}{c}\text { Smoking } \\
\%\end{array}$} & \multicolumn{2}{|c|}{$\begin{array}{c}\text { Overweight } \\
\%\end{array}$} & \multicolumn{2}{|c|}{$\begin{array}{c}\text { Physical inactivity } \\
\%\end{array}$} \\
\hline & $\mathrm{F}$ & M & $\mathrm{F}$ & M & $\mathrm{F}$ & M & $\mathrm{F}$ & M & $\mathrm{F}$ & $\mathrm{M}$ \\
\hline Alcohol misuse: & & & & & & $*$ & & & $*$ & $*$ \\
\hline yes & 3 & 27 & - & - & - & 63.0 & 66.7 & 40.7 & - & 29.6 \\
\hline no & 89 & 243 & - & - & - & 17.3 & 57.3 & 60.1 & 70.8 & 63.0 \\
\hline Smoking: & & & & $*$ & & & & & & $*$ \\
\hline yes & - & 59 & - & 28.8 & - & - & - & 62.7 & - & 40.7 \\
\hline no & 92 & 211 & 3.3 & 4.7 & - & - & 57.6 & 56.9 & 68.5 & 64.9 \\
\hline \multicolumn{11}{|l|}{ Overweight: } \\
\hline yes & 53 & 157 & 3.8 & 7.0 & - & 23.6 & - & - & 64.2 & 59.5 \\
\hline no & 39 & 113 & 2.6 & 14.2 & - & 19.5 & - & - & 74.4 & 59.8 \\
\hline Physical inactivity: & & & $*$ & $*$ & & $*$ & & & & \\
\hline yes & 63 & 161 & - & 5.0 & - & 14.9 & 54.0 & 58.4 & - & - \\
\hline no & 29 & 109 & 10.3 & 17.4 & - & 32.1 & 65.5 & 58.7 & - & - \\
\hline
\end{tabular}

*Indicate $\chi 2$ tests with $\mathrm{p}$-values $<0.05$

Tobacco use: Male doctors were more likely to use tobacco than female doctors $(\mathrm{M}=24.4 \%, \mathrm{~F}=2.2 \%)$; Table 1. The most popular type of tobacco in use by male doctors was cigarette, 59 (21.9\%), followed by pipe/cigar, 11 $(4.1 \%)$, then chewing tobacco, two $(0.7 \%)$ and snuff, two $(0.7 \%)$. However, the prevalence of smoking ten cigarettes or more daily was only $3.3 \%(n=270)$ in males. The cigarette smoking prevalence in males showed a significant inverse trend with age but the variations with marital status and specialty were not statistically significant (Table $2)$. No female doctor currently smoked cigarette but one smoked cigar (1.1\%) and the other chewed tobacco (1.1\%).

Overweight: In all, 210 (58.0\%) of Enugu doctors were estimated to be overweight ( $\geq 25 \mathrm{~kg} \mathrm{~m}^{-2}$ ). Both the male doctors and their female counterparts had similar overweight prevalences and mean body mass indices (Table 1). Using an old criteria(11) of overweight as BMI value $\geq 27.8 \mathrm{~kg} \mathrm{~m}^{-2}$ for males and $\geq 27.3 \mathrm{~kg} \mathrm{~m}^{-2}$ for females, the rate will be $\mathrm{M}=27.8 \%$ and $\mathrm{F}=32.6 \%$. Upto $34(12.6 \%)$ of the males and eleven $(12.0 \%)$ of the females have BMI $\geq 30 \mathrm{kgm}^{-2}$. The prevalence of overweight showed a positive linear trend with age in both sexes. The married state was linked with higher overweight rates but this was of borderline significance in males only while the specialty of the doctors had little influence on overweight behaviour in both sexes (Table 2). 
Sedentary lifestyle: Upto 224 (61.9\%) of these doctors do not engage in regular moderate- to- vigorous physical activity. The rate of physical inactivity was slightly higher for females $(68.5 \%)$ than males $(59.6 \%)$ though this difference was insignificant (Table 1). Sedentary lifestyle was also unrelated to marital status in both males and females. However, it was highly linked to age and specialty for males but not for females. Male doctors at extremes of age were more sedentary than others. Similarly, male doctors doing housemanship (78.6\%), medicine and laboratory medicine $(66.7 \%$ each) were most sedentary while general practitioners were most physically active (Table 2).

Related lifestyles: Table 3 shows the inter-relationship between the various behaviours for both sexes. There was a positive association between smoking versus alcohol misuse and smoking versus physical activity in males. A similar observation was noticed between alcohol misuse and physical activity in both sexes. No other significant relationship between behaviours was uncovered in both sexes.

The male doctors significantly had a slightly higher number of risky behaviours than the females (Table 1).

\section{DISCUSSION}

Of all the behaviours studied, alcohol misuse was the least reported irrespective of sex; and the men drank more than the women. This is expected since alcohol abuse is socially and culturally unacceptable in this part of Nigeria and even more so for females. Similar low rates of alcohol misues were found among men and women of corresponding educational level in Taiwan(12) and Sweden(13). In contrast, higher rates (>15\%) were reported by the 1900-1930 birth cohort of British male doctors(6). Infact our doctors of corresponding age claim not to abuse alcohol but then a younger birth cohort of British doctors would have been ideal for this comparison. And like this study respondents, the men in the above studies drank more than the women.

While their use of other forms of tobacco is much lower, the Enugu male doctors smoke cigarettes at a higher rate than the $10.8 \%$ measured for tertiary educated adults in a 1990/91 survey of 1270 adults living in medium sized towns/cities in Nigeria(5). Doctors also smoke more than the general population in Italy and Spain(5). However, the Enugu male doctors should imitate the exemplary smoking behaviour of doctors in Britain(14) and USA(15) who are the leading groups in smoking cessation and; as a result smoke much less than their general population. No female doctor is currently smoking cigarettes in contrast to the $6.7 \%$ prevalence recoded for females in the above mentioned Nigerian study. The reason for this may lie in their knowledge of the added health hazards of smoking to reproductive health since two thirds of them are married. Moreover like alcohol, the Nigeria society is less tolerant of a smoking female than a male and so these behaviours are largely male-dominated. The strong correlation between smoking and drinking in males reported in this survey has been noted by other investigators in the past $(6,12)$.

The mean BMI values and prevalences of overweight calculated in this study are in keeping with estimates for urban Africans(16) but higher than estimates obtained from people of the same educational level and job category in Taiwan(2) and the British Whitehall II(17) studies respectively. On comparison with the report of the 1988 1991 US National Health and Nutrition Examination Survey(11), the male doctors resemble the Black American men in their weight patterns while the female doctors resemble the non-Hispanic White American women and not the Black American women who are far heavier. And like the British, the non-Hispanic White and White Americans the female doctors on the average are lighter than their male counterparts. The opposite is true of the Black and non-Hispanic Black Americans. This finding may be related to the level of education of the study participants. The positive linear trend of BMI with age noted in this study has been previously reported $(11,12)$. The reality is that more than half of the doctors have BMI $\geq 25 \mathrm{~kg} \mathrm{~m}^{-2}$ and nearly one eighth have BMI $\geq 30 \mathrm{~kg} \mathrm{~m}^{-2}$. The contributing factor would be the observed sedentary lifestyle of these doctors, but then no direct correlation was found between the rates of physical activity and overweight. Also,the diet of these doctors need to be studied since excessive caloric intake has been implicated in the aetiology of obesity(18). Moreover cultural values should not be overlooked since an overweight appearance is a symbol of good living and affluence among Nigerians.

Irrespective of sex, physical inactivity is the most prevalent risky behaviour among Enugu doctors despite the beneficial effects of habitual exercise. Similar rates have been reported in the USA(19) while lower and higher rates were observed in the British Whitehall II study(17) and by Koong et al(12) in Taiwan, respectively. These comparisons are arbitrary since the measurement of physical activity in all these studies is crude and global standards are yet to be established. The adoption of sedentary lifestyle by these doctors is a direct reflection of firstly, the scarcity of government and communitysupported sport infrastructures in the city. Secondly, exercise programmes in workplaces in Nigeria is nonexistence. The positive association between physical activity and smoking or drinking reported here, has not been mentioned previously. It indicates that the few men that exercise during leisure hours do so at social-club sport facilities where other risky behaviours are hard to control. Although a few commercial gym facilities attached to beauty salons are available in the city for women, patronage is low, most probably as a result of cost and lack of motivation. The reported effect of specialty of the male doctors on participation in leisure physical activity has not been described in the past. The house officers are not typically sedentary when one considers the ambulatory nature of their job and their long working hours while the doctors in laboratory medicine cut a worrisome picture of a sedentary personality (sedentary working and leisure 
hours). The significant high level of physical activity $(55.6 \%)$ recorded for male general practitioners may be related to the opportunities for social interaction and patient catchment accorded to them by physical activity settings or could it be that general practitioners being true extroverts have chosen the right specialty in the first place? Therefore many psychosocial factors may be playing roles in the aversion to regular physical activity as has been suggested previously(4). The relationship between physical activity and personality and job type in our environment need to be explored since it may help identify those in need of exercise motivational programmes.

Interestingly, the lifestyle of the female doctors appear homogenous irrespective of age, marital status and specialty. Does the female doctors exhibit some peculiarity in lifestyle or does it reflect a strong sociocultural influence on female behaviour in this part of the country?

In conclusion, the risky behaviours commonly observed among these doctors are physical inactivity, overweight and cigarette smoking. Programmes to improve these habits are hereby advocated for these doctors.

\section{ACKNOWLEDGEMENTS}

To doctors who participated in this survey and all those who in various ways helped in data collection.

\section{REFERENCES}

1. Stafford M., Hemingway H., Stansfeld S.A., Brunner E. and Marmot M. Behavioural and biological correlates of physical functioning in middle aged office workers: the UK Whitehall II study. J. Epidem. Comm. Hlth. 1998; 52:353 -358.

2. Pyörälä K., De Backer G., Graham I., Poole-Wilson P., Wood D., Breithardt G.et al.Prevention of coronary heart disease in clinical practice: Recommendations of the Task Force of the European Society of Cardiology, European Atherosclerosis Society and European Society of Hypertension. Eur. Heart J. 1994; 15:1300 $-1331$.

3. Lindsay G.M. and Gaw A. Coronary heart disease prevention: A handbook for the health care team, lst edition, Edinburgh: Churchill Livingstone, 1997: 1- 334.

4. Report of a WHO scientific group. Cardiovascular disease risk factors: New areas for research. WHO Technical Report Series 1994; 841: 1- 46.

5. WHO.Tobacco or health: A global status report, Geneva; WHO, 1997: 1-495.

6. Doll R., Peto R., Hall E., Wheatley K. and Gray R. Mortality in relation to consumption of alcohol: 13 years' observation on male British doctors. Brit. Med. J. 1994; 309: 911 -918.

7. Chenet L., Mckee M., Leon D., Shkolnikov V. and Vassin S. Alcohol and cardiovascular mortality in Moscow: new evidence of a causal association. J. Epidem. Comm. Hlth. 1998; 52: 772 774.

8. WHO. Guidelines for controlling and monitoring the tobacco epidemic, 1st edition Geneva: WHO, 1998: 1-190.

9. Department of health. The health of the nation. London: HMSO, 1992: 57.

10. Wu leung W.T., Busson F. and Jardin C. Food composition tables for use in Africa, 15 Bethesda MD: USDHEW 1968: 218.

11. Kuozmarski R.J., Flegal K.M., Campbell S.M. and Johnson C.L. Increasing prevalence of overweight among US adults - The National Health and Nutrition Examination Surveys 1960 to 1991. J. Amer. Med. Ass. 1994; 272: 205 - 211.

12. Koong S.L., Malison M.D. and Nakashima A.K. A prevalence of behavioural risk factors in Taipei city, Taiwan. Int. J. Epidem. 1990; 19: 154 -159.

13. Romelsojö A., Leifman H. and Nyström S. A comparative study of two methods for the measurement of alcohol consumption in the general population. Int. J. Epidemiol. 1995; 24:929-936.

14. Doll R., Peto R., Wheatley K., Gray R. and Sutherland I. Mortality in relation to smoking: 40 years observations on male British doctors. Brit. Med. J. 1994; 309: 901 -910.

15. CDC. Smoking - related mortality decline among physicians Rhode Island. Morbid. Mortal. Wkly. Rev. 1990; 39:656-658.

16. Mbanya J.C.N., Minkoulou E.M., Salah J.N. and Balkau B. The prevalence of hypertension in rural and urban Cameroon. Int. J. Epidem. 1998; 17:181 - 185.

17. Marmot M.G., Smith G.D., Stansfeld S., Patel C., North F. and Head J.et al. Health inequalities among British civil servants: the Whitehall II study. Lancet 1991; 337:1387 -1393.

18. Prentice A.M. and Jebb S.A. Obesity in Britain:gluttony or sloth? Brit. Med. J. 1995; 311:437-439.

19. CDC. Prevalence of sedentary lifestyle. Morbid. Mortal. Wkly. Rev. 1993; 42: 576 - 579. 